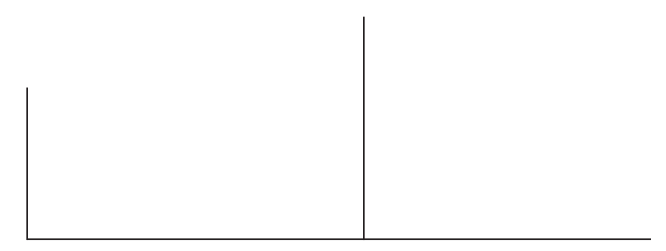

Rev. Latinoam. Psicopat. Fund., IV, 1, 94-105

\title{
Oposição e conflito na metapsicologia da angústia*
}

\author{
Paulo de Carvalho Ribeiro
}

\begin{abstract}
Partindo da existência de diferentes graus e efeitos da angústia, busca-se estabelecer uma associação da angústia psicótica com a prevalência de uma oposição não conflitiva entre as forças pulsionais disruptivas e os elementos de ligação, transformados em exigências de um supereu tirânico e aberrante. Algumas idéias de Jean Laplanche sobre a exclusividade das forças de desligamento no inconsciente são criticadas, levando, assim, à discussão sobre o recalcamento, bem como a questões relacionadas com a presença do conflito nas neuroses e sua ausência nas psicoses.
\end{abstract}

Palavras-chave: Angústia, psicose, supereu, conflito

* Texto apresentado no Grupo de Trabalho sobre Psicopatologia e Psicanálise do VIII Simpósio de Pesquisa e Intercâmbio Científico da ANPEPP, realizado em maio de 2000, em Serra Negra, SP. Muitas das reflexões aqui desenvolvidas foram inicialmente apresentadas no capítulo 7 do livro de nossa autoria intitulado $O$ problema da identificação em Freud: recalcamento da identificação feminina primária. 


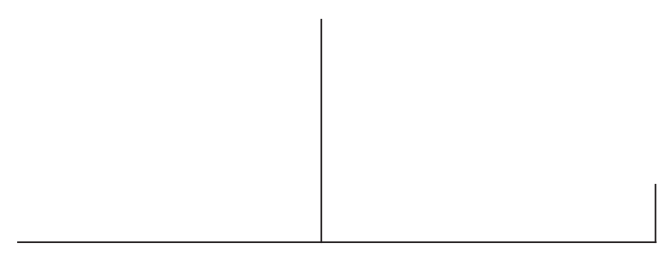

A distinção entre angústia como objeto de cura e angústia como objeto de escuta sugere, de imediato, a valorização de um aspecto tão essencial quanto evidente desse tipo de afeto, a saber, seus diferentes graus de intensidade e os diferentes efeitos psíquicos que a ele estão associados. $\mathrm{O}$ grande interesse que o tema da angústia adquire na clínica relaciona-se, portanto, à possibilidade de distinguir metapsicologicamente os processos psíquicos nos quais ela se origina. Para abordar esses processos, daremos especial importância às noções de oposição e conflito, buscando ressaltar a distinção entre elas e mostrar a relação de cada uma com diferentes momentos da constituição do aparelho psíquico.

Oposição e conflito são também noções que, como veremos, evocam questões antigas, como o caráter unificador do eu e das identificações, bem como a idéia de que as falhas nessa função de unificação relacionamse diretamente com as manifestações mais graves das psicoses.

Apesar da crítica lacaniana à compreensão das psicoses em termos de déficit da capacidade de síntese do eu, não vemos como evitar a idéia de clivagem do psiquismo ao abordar determinados fenômenos psicopatológicos, nem como estabelecer uma separação significativa entre clivagem e déficit da função de síntese, principalmente se levamos em conta que esses termos sempre nos remetem aos primeiros momentos de constituição do sujeito.

De fato, a discussão sobre as origens do sujeito psíquico, sobre a constituição da tópica psíquica e sobre o surgimento das instâncias do aparelho psíquico é uma tarefa indispensável para a compreensão dos diferentes tipos de angústia. Portanto, antes de propormos algumas diretrizes que nos parecem fundamentais para o manejo da angústia na clínica, será necessário apresentar, sucintamente, algumas reflexões metapsicológicas sobre os recalcamentos originário e secundário, o surgimento da pulsão, do eu e do supereu.

Considerando que, em psicanálise, o termo "angústia" quase invariavelmente está associado, direta ou indiretamente, à castração, começaremos 


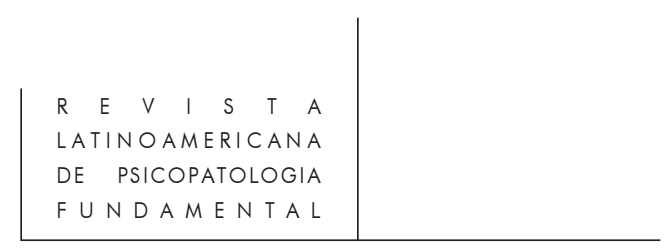

nossas reflexões metapsicológicas a partir de um debate crítico com algumas idéias de J. Laplanche sobre o estatuto do Édipo e da castração no inconsciente.

Édipo e castração têm sido tratados, nos textos mais recentes de Laplanche, como uma espécie de entrave na apreensão do sexual propriamente dito, ou seja, do sexual inteiramente comprometido com as forças de dispersão e com o caráter "demoníaco" e disruptivo das pulsões parciais. Em seu Court traité de l'inconscient, por exemplo, Laplanche (1993: 86) propõe uma separação nítida entre o recalcado originário e o secundário. Ele acaba por estabelecer, assim, a existência de dois níveis bem distintos do inconsciente: o primeiro se encontraria sob a influência exclusiva da pulsão sexual de morte, logo do princípio de desligamento (déliaison), enquanto o segundo, como sede do processo primário, comportaria uma luta entre as pulsões sexuais de morte e de vida, estas últimas assimiladas às forças de ligação.

Édipo e castração, por serem tentativas de simbolização e organização de elementos pulsionais dispersos e fragmentados, são, assim, concebidos como pertencentes às camadas menos profundas do inconsciente, nas quais a sexualidade genital vem sobrepor-se defensivamente ao sexual propriamente dito, ou seja, ao sexual desvinculado da diferença anatômica dos sexos.

Ora, se o inconsciente originário é, como afirma Laplanche, o "império do desligado", ou seja, uma espécie de cultura pura da pulsão sexual de morte, cabe perguntar quais as evidências (ou pelo menos os indícios) da existência desta sexualidade restrita ao desligamento e as razões de lhe conferir o que poderíamos chamar de uma marca de autenticidade do sexual.

Ao contrário de Laplanche, não fazemos distinção entre o que seria uma "cultura pura de alteridade", dominada pela dispersão absoluta, e uma alteridade impura em que vigoraria o processo primário. Mesmo admitindo a possibilidade de diferentes níveis do inconsciente, afirmamos que em seu nível mais profundo, ou seja, no próprio objeto-fonte da pulsão, já se encontram elementos de ligação e desligamento.

Para sustentar essa concepção do inconsciente e apresentar os fundamentos de nosso desacordo com Jean Laplanche, impõe-se uma análise crítica de algumas de suas posições teóricas, dentre as quais destacamos a teoria tradutiva do recalcamento e o conceito de objeto-fonte da pulsão.

\section{Teoria tradutiva do recalcamento}

Tomando como ponto de partida a teoria da sedução generalizada, Laplanche concebe os primeiros momentos constitutivos do aparelho psíquico como um processo em que o adulto, desconhecedor de sua sexualidade inconsciente, implanta mensagens sexuais enigmáticas na "derme psicofisiológica" da criança. Esta última, ao traduzir de forma incompleta as mensagens enigmáticas do adulto, produz 


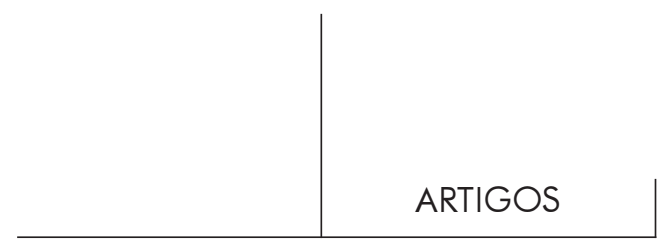

restos não traduzidos que se tornam os objetos-fonte da pulsão. Considerando que essa concepção tradutiva do recalcamento, inspirada nas formulações apresentadas por Freud na carta 52, é válida tanto para o recalcamento secundário quanto para o originário, a seguinte questão deve ser formulada: quem traduz, já que, no caso do recalcamento originário, ainda não existe um eu a quem poder-se-ia atribuir a iniciativa da tradução?

"O indivíduo biopsíquico" traduz, responde Laplanche (1999). É preciso, então, que nos perguntemos sobre os recursos de que dispõe esse "indivíduo" e também sobre a natureza exata dessa primeira tradução responsável pela formação do eu e do inconsciente.

A propósito das primeiras mensagens, Laplanche é muito claro: elas são externas, bem concretamente implantadas na periferia do indivíduo, principalmente nos pontos que serão denominados zonas erógenas. São, então, mensagens sensoriais.

Se nos voltamos agora para a tradução, Laplanche nos diz que se trata de uma metábola recalcante. Para que esse processo tradutivo se inicie, é preciso que a mensagem enigmática "se apresente para uma primeira tradução pelo sujeito". Contudo, além dessa intencionalidade semiológica da mensagem, é preciso também supor que a criança tenha a capacidade de se interrogar sobre ela. De fato, para Laplanche, nos primeiros significantes enigmáticos parentais, o significado é simplesmente substituído por um ponto de interrogação: “o que ele quer de mim?" se perguntaria o bebê.

"O que ele quer de mim?" é, com certeza, um modo de dizer. Não é difícil imaginar que ao supor que a criança se interrogue dessa forma, Laplanche queira simplesmente indicar a suscetibilidade do bebê ao enigma do adulto. Mas é precisamente aí que, ao nosso ver, se encontra todo o problema. Sem dúvida, o lactente não é um ser fechado para o mundo; ele é dotado de montagens psicofisiológicas e capaz de atenção e de interação. Mas será que isso basta para podermos supor que ele tenha essa capacidade de se interrogar? A suscetibilidade ao enigma do outro não demandaria uma instância muito mais complexa que o indivíduo biopsíquico, cujas montagens reguladoras estão, no que concerne ao psiquismo, num nível ainda muito elementar? E mesmo se aceitamos que o lactente é capaz de se interrogar, ainda teríamos de nos perguntar por que ele seria mais suscetível ao enigma, tal como Laplanche o concebe, do que a outras experiências corporais que lhe são impostas.

Além disso, cabe ainda perguntar o seguinte: se, como afirma Laplanche, o inconsciente não é o resultado de uma ação autocentrada, como, por exemplo, a que participa da identificação e da projeção, por que ele seria o resultado de uma tradução que, evidentemente, demanda, da mesma forma, um centro capaz de atividade tradutiva? 


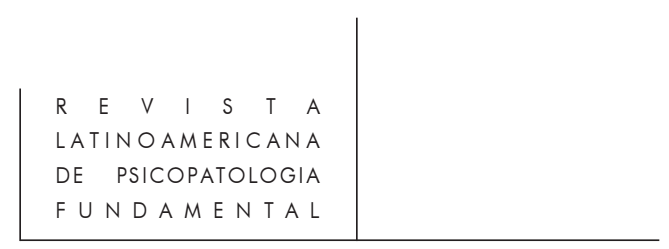

A segunda parte de nosso questionamento sobre a teoria tradutiva do recalcamento originário diz respeito à formação do eu-instância. Para ir direto ao ponto que nos interessa, gostaríamos de formular a seguinte questão: se admitimos que o eu-instância é formado a partir do surgimento de uma imagem da totalidade corporal e que essa imagem é formada de acordo com o modelo de totalidade corporal do outro, que tipo de metábola recalcante ${ }^{1}$ poderia produzir este efeito, e de onde vem a iniciativa da tradução neste caso? Em outros termos, se as primeiras mensagens são bem concretamente implantadas na periferia corporal e se, ao lado da imaturidade neurofisiológica, elas são determinantes da fragmentação do corpo, não seria então o caso de pensar que esta primeira tradução é, na verdade, uma primeira unificação desse corpo fragmentado, e que ela não é um trabalho do bebê, mas sim o resultado do narcisismo do adulto sobre o bebê?

Mesmo admitindo a idéia de que as mensagens do adulto são carregadas de conteúdos sexuais inconscientes, propomos explicar o caráter sexual-pressexual das primeiras excitações trazidas pelo adulto, não a partir de seu teor enigmático, mas a partir do fato de que essas excitações, inicialmente desprovidas de sujeito e de uma representação do corpo próprio, tornar-se-ão, a posteriori, excitações de um corpo cuja projeção psíquica virá revelar sua exposição inicial a todas as penetrações e intrusões provenientes do outro.

O eu-instância surge como representação da totalidade do corpo e pode ser entendido como uma projeção psíquica da imagem que se precipita na medida em que as vivências de fragmentação passam a ser entremeadas de experiências em que o narcisismo do adulto logra organizar e conter, sempre de forma parcial e provisória, a dispersão auto-erótica originária. Contudo, o corpo do qual o eu-instância é a representação só pode ser o avesso desse corpo fragmentado e "invadido" pelas mensagens sexuais inconscientes do outro. A constituição do eu-instância apresenta-se, portanto, como um processo simétrico ao recalcamento das vivências de excitação, cujo caráter intrusivo, fragmentador e excessivo foi revelado por sucessivos momentos em que prevaleceu uma precária delimitação corporal.

\section{Objeto-fonte da pulsão}

Essa concepção do recalcamento originário acarreta uma concepção do objeto-fonte da pulsão como um corpo precariamente unificado, submetido ao excesso de excitação e exposto a todo tipo de penetração de suas fronteiras epidérmicas. Mesmo considerando que se trata de um corpo instável e precariamente constituí-

1. Para maior precisão sobre a noção de "metábola", utilizada por Laplanche, ver Novos fundamentos para a psicanálise, p. 140 e seguintes. 


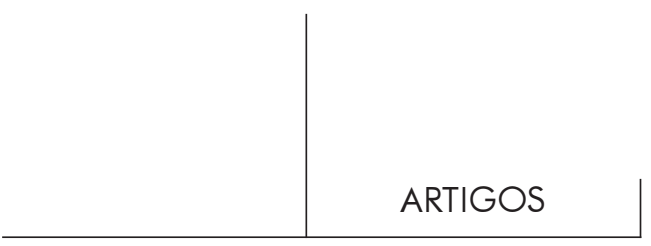

do, é evidente que ele comporta elementos de unificação. Essa concepção do objeto-fonte da pulsão, que parece tão distante das posições mais recentes adotadas por J. Laplanche (1987: 145), encontra, no entanto, uma confirmação na seguinte passagem dos Novos Fundamentos:

É o mesmo objeto que é, ao mesmo tempo, fonte das pulsões de vida e de morte, fonte tanto dos aspectos mortíferos quanto dos aspectos sintetizantes da pulsão, segundo o aspecto fragmentado e parcial, ou total que ele adquire. É o mesmo objeto-fonte que é, ao mesmo tempo, índice e objeto, objeto parcial e objeto total.

Como já mencionamos, em seu Curto tratado do inconsciente, publicado 6 anos depois dos Novos fundamentos, Laplanche (1993: 86) concebe o recalcado originário como um domínio exclusivo da pulsão de morte e das forças de fragmentação que a caracterizam. Nesse caso, o objeto-fonte da pulsão é concebido como um amontoado de significantes dessignificados, de representações-coisa que não estabelecem entre si nenhum tipo de associação ou influência, permanecendo completamente isolados uns dos outros. A seguinte passagem ilustra essa concepção:

Para dizer as coisas em poucas palavras, a tradução trata a mensagem como um todo coerente, ao passo que os significantes não traduzidos não são coerentes entre si, e não formam uma outra cadeia; o recalcamento, face negativa da tradução da mensagem enigmática, tem um efeito de deslocação (dislocation).

Num outro nível do inconsciente, o do recalcado secundário, estariam em vigor os mecanismos de condensação e deslocamento do processo primário, nos quais se manifestam as forças de atração entre as diversas representações recalcadas. Diferentemente do recalcado originário, o secundário seria um domínio misto das pulsões de vida e de morte.

Parece-nos claro, portanto, que existe, nesses diferentes momentos do pensamento de Laplanche, duas concepções nitidamente diferentes do objeto-fonte da pulsão. Na primeira delas, além de ser único (ou, pelo menos, um conjunto de elementos articulados entre si), ele comporta tanto os elementos de unificação quanto de fragmentação, o que reflete sua dupla identidade, total e parcial. Na segunda, ele parece ser múltiplo, desarticulado e restrito aos elementos de fragmentação.

Se temos razão em distinguir essas duas concepções do objeto-fonte, propomos conciliá-las dizendo que o recalcamento originário cria o eu-instância e um objeto-fonte único, a saber, o que chamaremos de corpo invadido originário, denominação que tomamos de empréstimo a Jacques André (1995). Em vez de afirmar que "a tradução trata a mensagem como um todo coerente", como faz Laplanche, diremos que, no recalcamento originário, a tradução conduzida pelo aporte narcísico do adulto transforma as mensagens sensoriais dispersas num todo cuja coerência depende da exclusão das experiências corporais transformadas, a posteriori, em experiências de invasão, fragmentação e desorganização. 


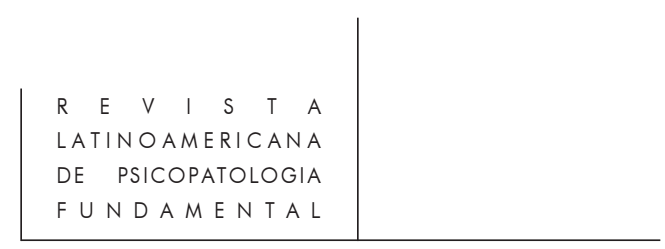

Pode-se concluir, então, que o objeto-fonte é inicialmente único e que ele se multiplica com o recalcamento secundário. Consideramos, portanto, que Laplanche está certo ao afirmar que o processo primário começa com o recalcamento secundário, mas discordamos dele tanto no que diz respeito à natureza do recalcado originário quanto no que tange à distinção esquemática de dois níveis do inconsciente. Não pensamos que o recalcado originário seja um amontoado de significantes dessignificados, sem nenhuma coordenação entre eles, e também não pensamos que exista um inconsciente mais puro (dominado pela pulsão de morte) e um outro menos puro (contaminado pelas forças de unificação que vigoram no processo primário). Defendemos o ponto de vista de que as leis que regem o inconsciente são as mesmas em todos os níveis. Em outras palavras, pensamos que a existência de dois tipos de recalcamento não implica a existência de dois tipos de funcionamento do inconsciente, mas sim que o recalcamento secundário é indispensável para transformar em conflito psíquico sexual o que era apenas uma oposição pressexual não conflitiva entre o eu e o corpo invadido originário.

É, portanto, essa distinção entre oposição e conflito que nos parece essencial para que possamos compreender a participação necessária do sexuado, ou seja, da diferença dos sexos e dos gêneros, na formação do sexual.

\section{Oposição e conflito na origem do sexual}

Para Laplanche, todas as questões relativas à diferença anatômica dos sexos e à diferença dos gêneros, bem como todas as questões sobre a identidade e a identificação, devem ser situadas do lado da defesa contra o ataque pulsional. Tomando como ponto de partida a língua alemã, na qual os dois sentidos da palavra "sexual" são expressos por duas palavras completamente diferentes (Geschlecht para designar tudo aquilo que diz respeito à existência de dois sexos, e Sexual para tudo aquilo que tange à sexualidade), Laplanche (1980: 310 e ss.) não hesita em afirmar que sexuar pode servir a dessexualizar.

Nosso principal argumento contra esse ponto de vista baseia-se numa distinção entre oposição e conflito, sobre a qual falaremos em seguida.

Partimos do princípio de que não existe sexualidade sem conflito. E para que haja conflito psíquico é indispensável que haja interdição. Contudo, é importantíssimo considerar que o valor que Freud atribuiu à idéia de interdição não teria tido a importância que conhecemos se ele não tivesse precisado sua natureza sexual.

Ora, se a interdição associada ao conflito inerente à sexualidade não é, portanto, de natureza autoconservativa, as forças de fragmentação que agem no inconsciente só podem ser consideradas propriamente sexuais sob condição de ameaçarem alguma coisa além da integridade corporal, já que, se a ameaça a isso se 


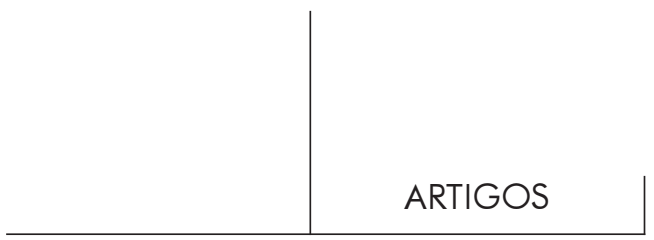

reduzisse, seríamos conduzidos a uma concepção equivocada do conflito psíquico na qual a sexualidade se oporia à autoconservação.

Da mesma forma, a dificuldade em conceber o conflito psíquico não seria menor se as forças de fragmentação não demandassem fazer-se representar pela consciência. Nesse caso, estaríamos limitados a uma simples oposição em que as forças de unificação do eu e as de fragmentação do recalcado originário não disputariam um mesmo lugar no sistema preconsciente-consciente.

O conflito psíquico deve sempre ser pensado levando-se em conta diferentes quantidades de força (ponto de vista econômico), oposição entre forças (ponto de vista dinâmico) e concorrência pelo espaço mental da consciência (ponto de vista tópico). Podemos pensar, então, que o que diferencia oposição e conflito do ponto de vista metapsicológico é a presença da dimensão tópica no conflito, ao passo que ela encontra-se ausente quando se trata de oposição.

A partir dessa distinção, pode-se concluir que entre recalcado originário e eu não há conflito, já que eles não disputam um mesmo espaço psíquico: eles se nutrem reciprocamente da oposição que lhes garante a existência como dois espaços psíquicos heterogêneos.

Essas considerações conduzem à seguinte hipótese: a existência do conflito é dependente de uma outra oposição, capaz de reproduzir, no espaço psíquico do eu, a oposição entre o próprio eu e o recalcado originário. As teorias sexuais infantis, o Édipo e a castração são as principais evidências dessa inclusão, no eu, de uma oposição que lhe era externa.

A oposição interna ao eu, indispensável para que o conflito psíquico se instale, deve ser forçosamente a reprodução da oposição originária na qual tanto as forças de unificação quanto as de fragmentação encontrarão representações que a elas sejam apropriadas. Essas representações, entretanto, são sempre sexuadas, e é por isso que a sexualidade, enquanto indissociável do conflito psíquico, encontra-se invariavelmente entrelaçada com a diferença dos sexos e dos gêneros.

O caminho para explicar as razões pelas quais essa reprodução da oposição originária sempre inclui as representações sexuadas já foi traçado por Jacques André. O tempo extremamente limitado dessa exposição impede qualquer aprofundamento sobre as idéia desse autor ${ }^{2}$. Restringir-nos-emos, portanto, a dizer que o maior mérito que vemos em suas idéias sobre as origens femininas da sexualidade situa-se na demonstração da proximidade, ou até mesmo da sobreposição,

2. Para uma exposição detalhada e crítica das idéias de Jacques André sobre a feminilidade originária, remetemos o leitor interessado ao capítulo 7 do livro $O$ problema da identificação em Freud: recalcamento da identificação feminina primária, onde se encontram também várias idéias sobre o supereu e as psicoses, que serão apresentadas em seguida. 


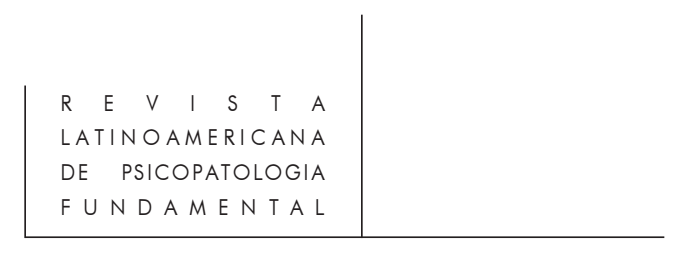

existente entre as representações da feminilidade e a situação de sedução originária, tal como descrita por Laplanche (1992a).

Porém, ao contrário de Jacques André e de Jean Laplanche, que vêem no complexo de castração apenas uma tentativa de simbolizar e conter uma sexualidade mais primitiva e demoníaca, consideramos que a prevalência da oposição fálico/ castrado no inconsciente encontra-se inteira e inextricavelmente associada à transformação do caráter pressexual do corpo invadido originário em algo propriamente sexual, ou seja, em moções pulsionais cuja exigência de ser penetrado e de gozar passivamente entram em conflito com as representações fálicas, ligadas à atividade e comprometidas com as funções defensivas do eu.

\section{Angústia neurótica e conflito, angústia psicótica e oposição}

Todas essas questões, discutidas até aqui, relacionam-se de várias formas com o problema da angústia. No entanto, um aspecto, a saber, a distinção entre oposição e conflito, destaca-se dos demais na medida em que apresenta uma via privilegiada de ligação com o tema do supereu e sua relação com a angústia.

Comecemos nossa abordagem dessa questão com a seguinte afirmação: muito mais do que uma tradução da "invasão inominável" sofrida pela criança originariamente seduzida, Édipo e castração são sempre uma espécie de tratamento narcísico e sexuado de tudo aquilo que originariamente se apresenta como uma oposição pressexual e ainda não conflitiva. Em outras palavras, o complexo de Édipo deve ser visto como experiências, em grande parte conscientes, em que fantasias e teorias sexuais infantis sobre pai e mãe, homem e mulher, masculino e feminino, penetrante e penetrado etc., tentam, obstinadamente, estabelecer um compromisso possível entre diferenças e oposições sexuadas, cujas raízes encontram-se na oposição inicial entre o eu e o recalcado originários.

Nessa concepção do Édipo, o supereu deve ser visto como uma convergência conflitiva da pulsão, do ideal e da interdição. Dentro de uma visão antropomórfica, o supereu não seria apenas um agente que exige do eu a renúncia da satisfação pulsional e o reconhecimento da realidade, mas principalmente o responsável pela transformação da invasão originária em identificação sexual e sexuada. Podemos, no entanto, abrir mão de pensá-lo como uma terceira instância entre o eu e o isso, para pensá-lo, nas neuroses, como sendo o próprio compromisso, e tendo como expressão paradigmática o conflito.

Ao contrário das neuroses, em que o supereu é a expressão de um compromisso, nas psicoses, ele aparece como uma clivagem.

No verbete "clivagem do eu", do Vocabulário, Laplanche e Pontalis ressaltam que, apesar das muitas dificuldades que encontra ao abordar o tema das psicoses, 


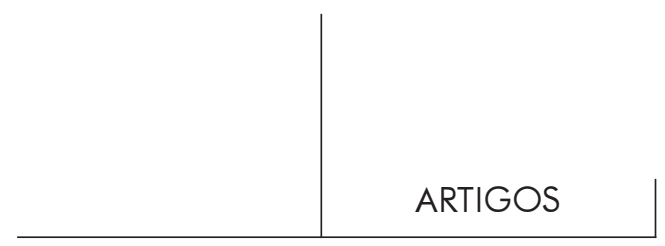

Freud lança mão da idéia de clivagem do eu, aproximando-se assim de Breuler que, partindo de uma outra concepção teórica, havia empregado o termo Spaltung em associação direta com a esquizofrenia. Sobre isso, julgamos importante assinalar que, ao admitir não saber se a clivagem do eu era uma noção evidente e desde há muito conhecida, ou algo novo e surpreendente, Freud (1940[1938]: 309) nos dá subsídios para pensar que sua dúvida tem origem na sobreposição de duas formas de conceber a clivagem: uma, antiga e evidente, encontra-se inteiramente relacionada com o conflito psíquico neurótico e refere-se aos efeitos, sobre o eu, da cisão consciente/inconsciente, ou seja, refere-se ao eu como sede do conflito entre as exigências da realidade, do ideal e da pulsão; outra, nova e surpreendente, relaciona-se com a psicose e tem como principal característica a ausência de conflito, ou seja, o fato de que duas correntes psíquicas contraditórias coexistem no eu sem entrar em confronto uma com a outra. Mas, diferentemente de Freud, não consideramos que a clivagem se dê, no segundo caso, apenas entre uma corrente normal, que leva em conta a realidade, e outra, patológica, que a recusa. Achamos muito mais provável que, ao lado de setores do psiquismo nos quais o conflito pode se estabelecer ( setores que podemos considerar normais e/ou neuróticos), existam outros, psicóticos, em que não há conflito, mas apenas oposição entre duas alteridades absolutas, que se alternam no espaço psíquico em que deveria existir o eu.

Se, nas neuroses, o complexo de Édipo é um processo que assegura o compromisso conflitivo de elementos oriundos da clivagem inaugural e que eram mantidos numa relação de pura oposição; nas psicoses, as vicissitudes do Édipo (ou do que deveria sê-lo) desfavorece a formação de compromisso e instala uma clivagem absoluta, não conflitiva, em que o eu deveria se consolidar.

A maior parte dos fenômenos psíquicos que observamos nas psicoses sugerem essa clivagem. Seja no sentido da fragmentação, como, por exemplo, as manifestações diretamente ligadas às transformações corporais, vividas, de forma alucinatória, como decomposições e transformações dilacerantes; seja no sentido inverso, quando as forças de ligação aparecem deformadas pela criação delirante de "autoridades", cujas marcas distintivas são apenas a arbitrariedade e a crueldade incomensuráveis. É, contudo, fundamental esclarecer que não se trata aqui da expressão direta ou exclusiva dos restos não traduzidos das implantações sexuais originárias. Mesmo sendo relacionadas a esses elementos, são as vicissitudes do Édipo, ou seja, os efeitos psíquicos ligados à descoberta da diferença anatômica dos sexos e à função paterna que determinam essas vivências psicopatológicas. $\mathrm{O}$ que permite supor a existência de um supereu tirânico e pulsional nas psicoses não é apenas a "invasão inominável”, pois a natureza essencialmente corporal dessa invasão não bastaria para gerar a complexidade sádica dos imperativos categóricos que caracterizam o supereu nas psicoses. Para que essa desmesura pulsional e mortífera vigore, é indispensável que o Édipo se instale e fracasse em sua função de 


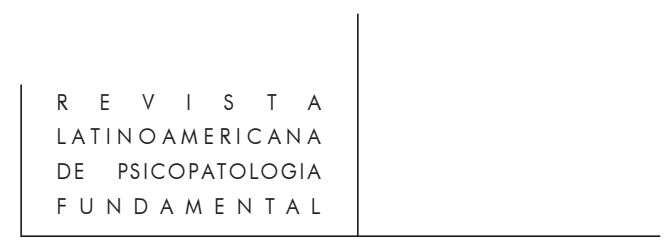

formar compromissos. Nesse caso, ao contrário de se tornar uma espécie de afetação mútua das forças de ligação e desligamento, o supereu usurpa a função egóica e manifesta-se ora como alteridade pulsional que parasita um corpo aviltando-o, ora como alteridade tirânica, que impõe tanto esse aviltamento quanto a punição não menos aviltante do gozo que ele produz.

Como conclusão podemos, então, sugerir que a angústia neurótica, ligada ao conflito psíquico, pode ser vista tanto como uma energia precursora das formações de compromisso, quanto como um resto energético, um ruído, poderíamos dizer, produzido pelo atrito entre as exigências pulsionais disruptivas e as condições narcísicas e indentificatórias com as quais elas lutam. Em outras palavras, a angústia ligada ao conflito pode ser vista, numa espécie de movimento espiral, seja como um fator que instiga a realização de compromisso entre uma alteridade pulsional demoníaca e uma "alteridade" domesticada pelas identificações egóicas totalizantes, seja como um produto desse compromisso.

Por outro lado, a angústia psicótica, ligada à oposição, aparece como um fracasso do compromisso e apresenta-se sempre como vivências que se aproximam ou se confundem com a despersonalização, com a perda ou abalo das próprias fronteiras corporais e psíquicas do eu, acarretando, invariavelmente, uma profunda alteração das relações com a realidade, com a linguagem e com o próprio corpo.

\section{Referências bibliográficas}

ANDRÉ, J. Aux origines féminines de la sexualité. Paris: PUF, 1995.

FreUd, S. (1940[1938]). A divisão do ego nos processos de defesa. E.S.B. Rio de Janeiro: Imago, 1969. v. XXIII.

Laplanche, J. Problématiques II: Castration, symbolisations. Paris: PUF, 1980.

. Nouveaux fondements pour la psychanalyse. Paris: PUF, 1987.

Novos fundamentos para a psicanálise. São Paulo: Martins Fontes, 1992.

La position originaire du masochisme dans le champ de la pulsion sexuelle. In La révolution copernicienne inachevée. Paris: Aubier, 1992a. 1993.

. Court traité de l'inconscient. Nouvelle Revue de Psychanalyse, n. 48, pp. 69-96,

. Sublimatio et/ou inspiration. In Entre séduction e inspiration: l'homme. Paris: PUF, 1999.

Ribeiro, Paulo de C. O problema da identificação em Freud: recalcamento da identificação feminina primária. São Paulo: Escuta, 2000. 


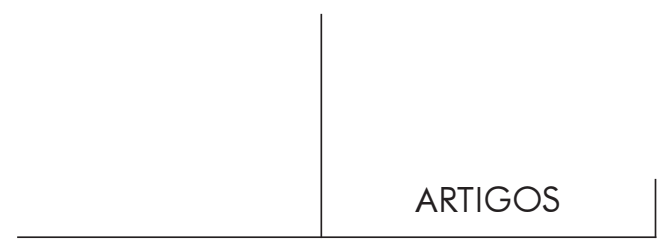

Resumos

Desde la existencia de diferentes grados y efectos de la angustia, se busca establecer una asociación de la angustia psicotica con la prevalencia de una oposición no conflictiva entre las fuerzas pulsionales disruptivas y los elementos de ligazón, transformados en exigencias de un superyo despotico y aberrante. Algunas ideas de Jean Laplanche sobre la exclusividad de las fuerzas de desligamento en el inconsciente son criticados, llevando, así, a la discusión sobre el recalcamento, así como a cuestiones relacionadas con la presença del conflicto en las neurosis y su ausencia en las psicosis.

Palabras llave: Angustia, psicosis, superyo, conflicto

L'existence de différents degrés d'angoisse est le point de départ pour la proposition de l'association de l'angoisse psychotique à la prévalance d'une opposition sans conflit entre les forces pulsionnelles disruptives et les éléments de liaison transformés en des exigences d'un surmoi tyrannique et aberrant. Quelques idées de Jean Laplanche sur l'absence d'éléments de liaison dans l'inconscient sont critiquées, ce qui mène à une discussion sur le refoulement et la distinction entre neurose et psychose à partir de la présence ou non du conflit psychique.

Mots clés: Angoisse, psychose, surmoi, conflit

The author uses the existence of varying degrees of anxiety as a stepping stone to propose that psychotic anxiety is associated with the predominance of non-conflictive opposition between disruptive drive-related psychic forces and binding narcissistic elements which are transformed into tyrannical and deformed demands of the superego. Some ideas of Jean Laplanche related to the exclusiveness of unbinding forces in the unconscious are analyzed. A discussion follows about repression and the role of psychic conflict as a determining factor in differentiating between neuroses and psychoses.

Key words: Anxiety, psychose, superego, conflict

Versão inicial recebida em outubro de 2000

Versão revisada recebida em fevereiro de 2001 